\title{
Scaleable ultra-thin and high power density graphene electrochemical capacitor electrodes manufactured by aqueous exfoliation and spray deposition
}

\author{
Beatriz Mendoza-Sánchez *, Bertold Rasche, Valeria Nicolosi, Patrick S. Grant \\ Department of Materials, University of Oxford, Parks Road, Oxford OX1 3PH, UK
}

\begin{abstract}
Graphene electrodes of high power density were manufactured by a surfactant-water based exfoliation method followed by a scaleable spray-deposition process. Cyclic voltammetry and galvanostatic charge-discharge experiments revealed a combination of electric double layer and pseudocapacitive behavior that, unlike the many graphene-oxide derived electrodes, was maintained to unusually high scan rates of $10,000 \mathrm{mV} \mathrm{s}^{-1}$, reaching a maximum capacitance of $543 \mu \mathrm{F} \mathrm{cm}$ and with a capacitive retention of $57 \%$ at $10,000 \mathrm{mV} \mathrm{s}^{-1}$. The performance of graphene electrodes was contrasted with carboxylated single walled carbon nanotubes that showed a sharp decrease in capacitance above $200 \mathrm{mV} \mathrm{s}^{-1}$. Electrochemical impedance spectroscopy analysis showed a fast capacitor response of $17.4 \mathrm{~ms}$ for as manufactured electrodes which was further improved to $2.3 \mathrm{~ms}$ for surfactant-free $40 \mathrm{~nm}$ thick electrodes. A maximum energy density of $75.4 \mathrm{nW} \mathrm{h} \mathrm{cm}{ }^{-2}$ gradually decreased as power density increased up to $2.6 \mathrm{~mW} \mathrm{~cm}^{-2}$. Graphene electrodes showed $100 \%$ capacitance retention for 5000 cycles at the high power scan rate of $10,000 \mathrm{mV} \mathrm{s}^{-1}$.
\end{abstract}

\section{Introduction}

Electrochemical capacitors are high power density and long cycle life electrochemical energy storage devices for applications where a high charge-discharge rate is required for short-term power management and delivery. For example, when combined with a battery, power pulses for short-term electrical demand in the millisecond range from electrochemical capacitors can extend the life and reduce the size of batteries in systems such as mobile phones where circuit RC times $<1 \mathrm{~s}$ are needed [1,2]. A further recently suggested high power application is alternating current line filtering that demands a high frequency capacitive response with RC times $<8.3 \mathrm{~ms}(120 \mathrm{~Hz})$ [3].

The energy storage mechanism of a electrochemical capacitor consists of the formation of an electrical double layer at an electrode-electrolyte interface where the overall capacitance and energy density is proportional to the surface area of the electroactive material [4]. For this reason, nanostructured high surface area carbon materials have been exploited for electrochemical capacitor applications, firstly activated carbon which is fully commercialized, and more recently, carbon nanotubes and then graphene $[5,6]$. Graphene consists of one-atom thick $\mathrm{sp}^{2}$-bonded carbon sheet forming a honeycomb two dimensional (2D) nanostructure with unique electronic properties: ambipolar electric field effect with high charge carrier (massless Dirac fermions) mobilities independent of temperature, and a room temperature quantum Hall effect [7-11]. These electronic properties and a theoretical surface area of $2600 \mathrm{~m}^{2} \mathrm{~g}^{-1}$ suggest that graphene may be a promising candidate material for electrochemical capacitor applications. However the realization of this potential in practice demands cost-effective and scaleable synthesis methods that preserve the key properties. Major challenges 
include: (1) obtaining defect-free graphene that preserves its intrinsic high electrical conductivity (if high power density is to be achieved), (2) synthesis of high surface area graphene with a high yield of mono- and bi-layer flakes, and (3) inhibition of graphene's natural tendency to restack.

In order to fully utilize the charge storage capability of nanostructured materials, the fabrication of binder-free thin-film electrodes is of paramount importance. Conventional electrode manufacturing techniques combine electroactive materials with polymeric binders that reduce considerably the surface area available for charge storage, introduce inert electrode materials that reduce gravimetric capacitance and increase electrode resistance. A reduced electrode thickness favours electrochemical utilization for enhanced energy density, and reduces electron and ionic resistance (short diffusion lengths) having an overall effect of enhanced power density. Hence, the concept of "microsupercapacitor" has emerged making reference to binder-free micrometer thick electrodes manufactured by a variety of techniques such as a combination of chemical vapor deposition (CVD) and etching (carbide derived carbons, 2-120 $\mu \mathrm{m}$, $80-180 \mathrm{~F} \mathrm{~cm}^{-3}$ depending on thickness [12]), CVD only (single-walled carbon nanotubes (SWCNTs), 100-500 $\mu \mathrm{m}$, $12 \mathrm{~F} \mathrm{~cm}^{-3}$ [13], multi-walled carbon nanotubes (MWCNTs) composites [14]), inkjet printing (carbon nanotubes [15], carbon, $1-2 \mu \mathrm{m}, 2.1 \mathrm{mF} \mathrm{cm}^{-2}[16]$ ), electrophoretic deposition (carbon onions, $7 \mu \mathrm{m}, 0.9 \mathrm{mF} \mathrm{cm}^{-2}, 1.3 \mathrm{~F} \mathrm{~cm}^{-3}[17]$ ), and micromachining (polymers, $0.03 \mathrm{~F} \mathrm{~cm}^{-2}$, [18]). Fabrication of sub-micrometer binder-free electrodes that maintain high energy density has proven to be more challenging. Particularly binder-free graphene electrodes of nanometer-scale thickness have been fabricated by plasma-enhanced chemical vapour deposition (PECVD) $\left(600 \mathrm{~nm}, 195 \mu \mathrm{F} \mathrm{cm}{ }^{-2}\right.$ [3]), CVD (few layers, $\left.80 \mu \mathrm{F} \mathrm{cm}^{-2}[19]\right)$, and chemical reduction of graphene oxide followed by a dip-dry deposition in a layer-by-layer assembly (10 nm, $394 \mu \mathrm{F} \mathrm{cm}$ c $\left.^{-2}[19]\right)$. High power density has been achieved by non-defective (on basal planes) graphene produced by PECVD and vertically oriented respect to the current collector [3], whereas energy density has been shown to be dependent not only on electrode thickness but also on graphene morphology [20], degree and type of porosity [2123], and the presence of surface chemical functionalities [24].

A popular method to produce graphene has been the exfoliation of graphene oxide followed by chemical/thermal/ microwave reduction combined with the manufacture of several micrometers-thick electrodes by the conventional method of adding binders [25-30]. This method produces "graphene" that contains a high fraction of residual oxides and structural defects located on the basal plane that provide an added pseudocapacitive effect [24] but undermine electronic conductivity $[27,31,32]$ which in turn reduces power density. Graphene oxide-derived graphene has also been combined with functionalized MWCNTs in thin-film electrodes (up to $400 \mathrm{~nm}$ ) manufactured by a layer-by-layer assembly technique with considerable gravimetric $\left(157 \mathrm{~F} \mathrm{~g}^{-1}\right)$ and volumetric capacitance $\left(144 \mathrm{~F} \mathrm{~cm}^{-3}\right)$, due to the presence of pseudocapacitive chemical groups and increased packing density of the electroactive material, but with comparative low power density $[24,33]$.
Most of the cited electrode fabrication methods poorly control deposited mass, film thickness, morphology and uniformity. Other problems include poor reproducibility, long processing times, high cost and low possibility for scalability. In this work, we exfoliate graphite to produce graphene suspended in water-surfactant solutions. This method allows us to produce un-oxidised graphene in solution with high yield and a low degree of defects $[34,35]$. The combination of this low cost and environmentally benign method with a scaleable spray-deposition technique allows the manufacture of nanometer-thick electrodes, both at laboratory and semiindustrial scale $[36,37]$. The performance of graphene electrodes is compared with that of carboxylated single walled carbon nanotubes of similar thickness, and shows unusual and potentially attractive high power density performance.

\section{Experimental}

\subsection{Materials}

Elicarb SWCNTs were supplied by Thomas Swan and Co. Ltd. (UK); graphite, sodium cholate $(\mathrm{NaC})(>99 \%)$, nitric acid $(69 \%)$ and hydrochloric acid (37\%) by Sigma-Aldrich (UK); poly (ethyleneimine) (PEI, Mw $=70,000$ ) by Alfa-Aesar (UK); indium tin oxide (ITO, $7 \Omega /$ sq sheet resistance) from Delta Technologies. Deionized water $(10 \mathrm{M} \Omega \mathrm{cm})$ was used for all processing.

\subsection{Graphene synthesis}

Graphene was produced as previously reported by Lotya et al. [34]. Graphite $(1.5 \mathrm{~g})$ was added to a $\mathrm{NaC}$ aqueous solution $\left(0.1 \mathrm{mg} \mathrm{ml}^{-1}, 300 \mathrm{ml}\right)$. Ultrasonication was carried out in a low power (Ultrawave U1250D, $200 \mathrm{~W}, 30-40 \mathrm{kHz}$ ) sonic bath $(51 \mathrm{~h})$. The resulting dispersion was then centrifuged (3000 rpm, $90 \mathrm{~min}$ ), and the supernatant containing the graphene was collected. The graphene concentration $C$ determined using the Lambert-Beer law for absorbance at $\lambda=660 \mathrm{~nm}$ and a extinction coefficient of $\alpha_{G}=6600 \mathrm{~L} \mathrm{~g}^{-1}$ $\mathrm{m}^{-1}$, was $\mathrm{C}=0.072 \mathrm{mg} \mathrm{ml}^{-1}$.

\subsection{SWCNT processing}

SWCNTs were steam purified as described elsewhere $[38,39]$. Subsequently, SWCNTs were carboxyl-functionalized by refluxing in $\mathrm{HNO}_{3}\left(69 \%, 30 \mathrm{~h}, 100^{\circ} \mathrm{C}\right)$ followed by filtration and extensive rinsing with deionized water until neutral $\mathrm{pH}$. Aqueous dispersions of carboxylated SWCNTs $\left(0.5 \mathrm{mg} \mathrm{ml}^{-1}\right)$ were produced by ultrasonication ( $600 \mathrm{~W}, 20 \mathrm{kHz}$ probe) for $12 \mathrm{~min}$ while keeping ice cooling.

\subsection{Electrode manufacture}

Electrodes of $1 \mathrm{~cm}^{2}$ area were spray-deposited onto ITO coated glass substrates by a method described elsewhere $[36,37]$. Briefly, suspensions of graphene or carboxylated-SWCNTs were fed into a industrial spray head where an atomizing air flow produced a suspension mist that was deposited onto the ITO substrates maintained at a temperature suitable for the immediate volatilization of the fugitive carrier liquid 
(water). The spray head was moved at a constant spray height and speed in a single direction above the target substrates to produce films of uniform thickness over the entire substrate area. Prior to the spray deposition of electroactive material, substrates were pre-coated with a $5 \mathrm{~nm}$ layer of $0.1 \% \mathrm{w} / \mathrm{w}$ PEI solution to improve adhesion of the electroactive material to the substrate. Electrodes were manufactured by spray-deposition of either a graphene or a carboxylated-SWCNT aqueous suspension. The average thickness of graphene, and SWCNT electrodes was $350 \mathrm{~nm}$ and $550 \mathrm{~nm}$ respectively. The average mass of spray deposited graphene electrodes was approximately read in a microbalance as $0.01-0.03 \mathrm{mg}$ (see next section). The same applies for SWCNT electrodes. A large area electrode, $A=1 \mathrm{~m} \times 0.15 \mathrm{~m}$, was spray-deposited onto an aluminium coated thin polymer web (polyethylene thereftalate (PET)) following a method previously described [36].

\subsection{Equipment and characterization techniques}

Absorption measurements were made using a Varian Cary 5000 UV-visible-NIR spectrometer; transmission electron microscopy (TEM) images were obtained with a JEOL 2010 operated at $200 \mathrm{kV}$; and Raman spectroscopy was performed with a JY Horiba Labram Aramis imaging confocal Raman microscope with a solid state laser of $532 \mathrm{~nm}$ wavelength (frequency doubled YAG) as excitation source. Surface chemical groups were characterized by X-ray photoelectron spectroscopy (XPS) in an ion pumped ESCA200 (Scienta-Gammadata ESCA 200 Upsala Sweden) equipped with a monochromatic $\mathrm{Al} \mathrm{K} \alpha$ source, with samples supported on ITO coated glass substrates. The analyzer operated at constant pass energy of $500 \mathrm{eV}$ for wide scans and $150 \mathrm{eV}$ for detailed scans. Electrode thickness was determined by step height measurements in a Dektak $6 \mathrm{M}$ profilometer (Veeco Instruments Inc.). The weight of deposited films was measured using a Sartorius microbalance with $0.01 \mathrm{mg}$ readability. Sheet resistance measurements of a $150 \mathrm{~nm}$ thick spray-deposited graphene film on glass substrates were performed using the Van der Pauw method and a Keithley 2400 source meter [40].

\subsection{Electrochemical characterization}

Graphene and SWCNT electrodes were tested in a three-electrode electrochemical cell configuration using a Reference 600/EIS300 Gamry potentiostat/galvanostat, Ag/AgCl electrode as reference, a platinum sheet as counter electrode, and $1 \mathrm{M} \mathrm{H}_{2} \mathrm{SO}_{4}$ as the electrolyte. Cyclic voltammetry and galvanostatic charge-discharge experiments were performed in a potential range from 0 to $1 \mathrm{~V}$ vs. $\mathrm{Ag} / \mathrm{AgCl}$. Electrochemical impedance spectroscopy (EIS) measurements were performed using a AC voltage of $5 \mathrm{mV} \mathrm{rms} \mathrm{in} \mathrm{the} \mathrm{frequency} \mathrm{range} \mathrm{of} 0.01$ $200 \mathrm{kHz}$ with a DC voltage of $0.396 \mathrm{~V}$.

\section{Results and discussion}

\subsection{Graphene characterization}

As exfoliated graphene was sprayed for few seconds onto holey-carbon TEM grids for characterization. Fig. 1a shows a low magnification image of exfoliated graphene monolayer and multilayer flakes. Fig. 1b shows the zoomed-in image (circled area) of a monolayer in Fig. 1a as confirmed by the corresponding electron diffraction pattern showed in Fig. 1c where the intensity profile $I$ along the $(1 \overline{2} 10)-(0 \overline{1} 10)-$ $(\overline{1010})-(\overline{2} 110)$ axis shows a $\mathrm{I}_{[1100} / \mathrm{I}_{\{2110\}}>1$, known as a signature for monolayer graphene [41-44]. According to Lotya et al. [34] and based on edge-counting of exfoliated graphene flakes, all thicker flakes consisted of less than 10 layers.

In order to characterize the nanostructure of graphene electrodes themselves, TEM grids were also sprayed in a continuous way for $15 \mathrm{~min}$ simultaneously with the spray
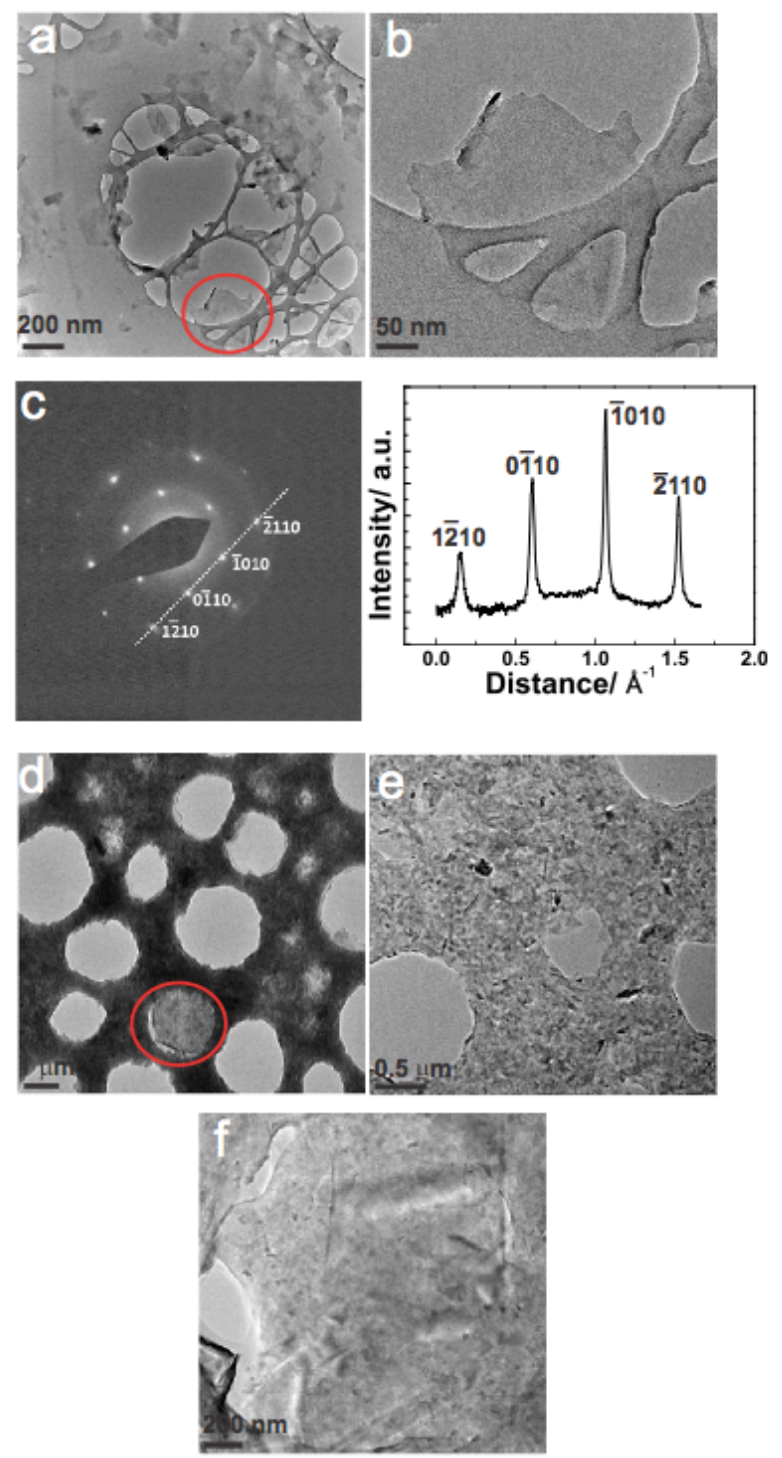

Fig. 1 - TEM images of graphene flakes. (a) A wide-field image showing several graphene flakes, (b) a higher magnification view of circled area in (a) of a monolayer graphene; (c) its corresponding diffraction pattern with a intensity profile along $(\mathbf{1} \overline{1} 110)-(0 \overline{1} 10)-(\overline{1} 010)-(\overline{2} 110)$ axis showing $I_{\{1100\}} / I_{\{2110\}}>1$; (d) a wide-field image of a 15 min spray-deposited graphene; (e) higher magnification view of (d); (f) higher magnification view of circled area in (d). 
deposition of electrodes onto current collector substrates. A full and uniform coverage of the grid was obtained and is shown in Figs. 1d and 1e. Notice that the non-covered areas are the holes in the holey-carbon TEM grid where graphene flakes passed through upon spraying. Fig. If shows a higher magnification view of the circled area in Fig. 1d indicating a small degree of restacking of graphene layers which may inhibit the ultimate electrochemical performance.

Spray-deposited electrodes were characterized by Raman spectroscopy and a representative spectrum is shown in Fig. 2. Three bands were present: a D band $\left(1340.9 \mathrm{~cm}^{-1}\right)$, a $\mathrm{G}$ band $\left(1571.4 \mathrm{~cm}^{-1}\right)$, and a $2 \mathrm{D}$ band $\left(2683.5 \mathrm{~cm}^{-1}\right)$ [45]. The degree of structural defects in graphene can be easily characterized by monitoring the $\mathrm{D}$ to $\mathrm{G}$ band intensity ratios $I_{D} / I_{G}$. Graphene prepared and sprayed according to our method showed $I_{D} / I_{G}=0.34$, which was much lower than the $I_{D} / I_{G}=0.57$ (mean value for graphene obtained by the same exfoliation procedure but with sonication times varying from 2 to $430 \mathrm{~h}$ ) reported by Lotya et al. [34], $I_{D} / I_{G}=0.67$ for graphene produced by PECVD [3], and $I_{D} / I_{G} \geqslant 1$ of reduced graphene oxide $[46,27,47]$, indicating that our processing methods did not result in the formation of significant quantities of defects $[41,48]$. Furthermore, the lack of broadening of the $G$ band, typical of graphene oxide or reduced graphene oxide Raman spectra (where the D band is also typically broad due to the numerous oxygen functionalities/defects on the basal plane of graphene oxide/reduced graphene oxide [49]) indicated that the $\mathrm{D}$ band intensity arose from edge defects rather than basal plane defects $[41,46,27]$. The shape of the $2 \mathrm{D}$ band was typical of multilayer graphene and consistent with the progressive deposition of a large number of graphene flakes on one another until full coverage was achieved.

XPS $C_{1 s}$ and $O_{1 s}$ photoemission peaks for the graphene electrodes are shown in Figs. $3 a$ and b, respectively, where each peak was deconvoluted into separate Gaussian-Lorentzian shape components to account for the contribution of different functional groups. The components of the $\mathrm{C}_{1 \mathrm{~s}}$ core line were assigned to $\mathrm{sp}^{2}(284.5 \mathrm{eV})$ and $\mathrm{sp}^{3}(285.1 \mathrm{eV})$ hybridized carbons, $\mathrm{C}-\mathrm{O}, \mathrm{C}-\mathrm{OH}$ bonds $(286.0 \mathrm{eV})$, and $-\mathrm{COOH}$ bonds $(288.3 \mathrm{eV})[50,45]$. The same functional groups were found by analysis of the $\mathrm{O}_{1 \mathrm{~s}}$ core line: $-\left(\mathrm{C}=\mathrm{O}^{*}\right)-\mathrm{OH}(531.0 \mathrm{eV}), \mathrm{C}-\mathrm{O}, \mathrm{C}-$ $\mathrm{OH}(532.3 \mathrm{eV}),-(\mathrm{C}=\mathrm{O})-\mathrm{O} * \mathrm{H}(533.2 \mathrm{eV})$, and adsorbed water

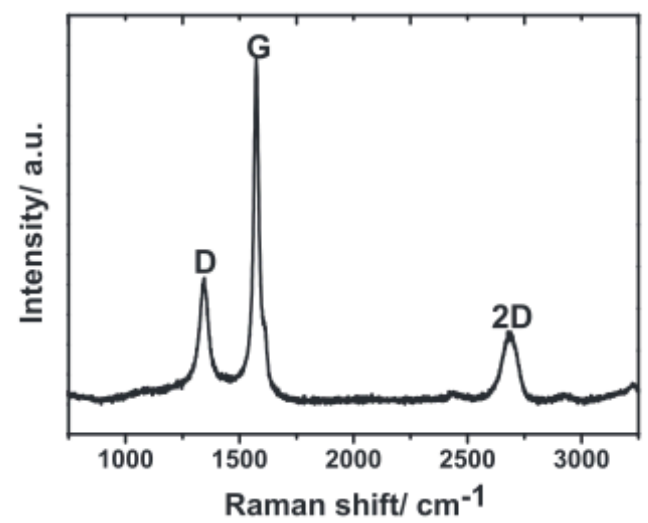

Fig. 2 - A Raman spectrum of a spray-deposited graphene electrode.
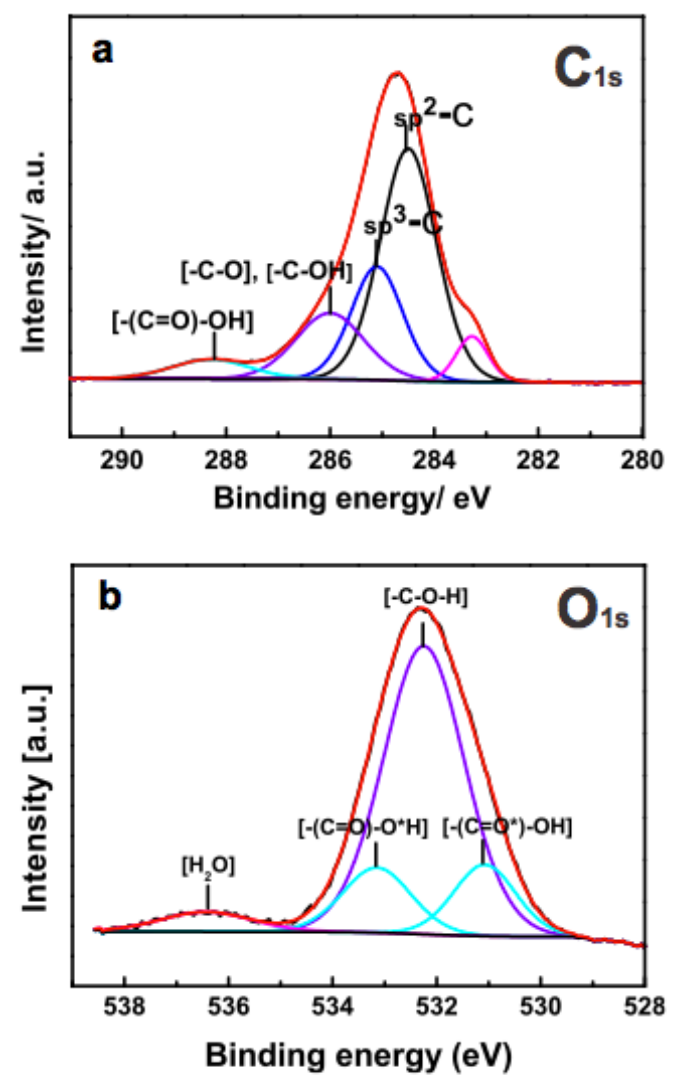

Fig. 3 - X-ray photoelectron spectroscopy of a spraydeposited graphene electrode: (a) $\mathrm{C}_{1 s}$, and (b) $\mathrm{O}_{1 \mathrm{~s}}$ spectra.

(536.4 eV) [51-53]. As supported by cyclic voltammetry studies (vide infra), the majority of detected oxygen containing functional groups, and the $\mathrm{sp}^{3}$ hybridized carbon contribution were due to the presence of $\mathrm{NaC}$ molecules that remained attached to graphene sheets prior, during and after spray deposition, with only a minor contribution of graphene edge defects $[54,55]$.

\subsection{Electrochemical characterization of graphene electrodes}

Graphene electrodes of $350 \mathrm{~nm}$ thickness were characterized by cyclic voltammetry in $1 \mathrm{M} \mathrm{H}_{2} \mathrm{SO}_{4}$ in a $1 \mathrm{~V}$ voltage window at a range of scan rates. Fig. 4 a shows cyclic voltammograms at scan rates of $10,50,100,200,300,400$ and $500 \mathrm{mV} \mathrm{s}^{-1}$ with a quasi-rectangular shape and redox-type peaks at approximately $0.4 \mathrm{~V}$. There was a combination of pseudocapacitance and double layer capacitance that was maintained at unusually high scan rates of $10,000 \mathrm{mV} \mathrm{s}^{-1}$ as shown in Fig. $4 \mathrm{~b}$. This high scan rate behavior is in marked contrast to most of the graphene oxide-based electrochemical capacitor electrodes reported to date where significantly resistive behavior is developed at scan rates as low as $100 \mathrm{mV} \mathrm{s}^{-1}$ and not higher than $1000 \mathrm{mV} \mathrm{s}^{-1}$ (in both aqueous and organic electrolytes) [25-29,56]. The high power capability of the graphene electrodes can be attributed to: (1) the pristine nature of the graphene produced by exfoliation that preserves the integrity of the $\mathrm{sp}^{2}$ bonding configuration and therefore intrinsic 

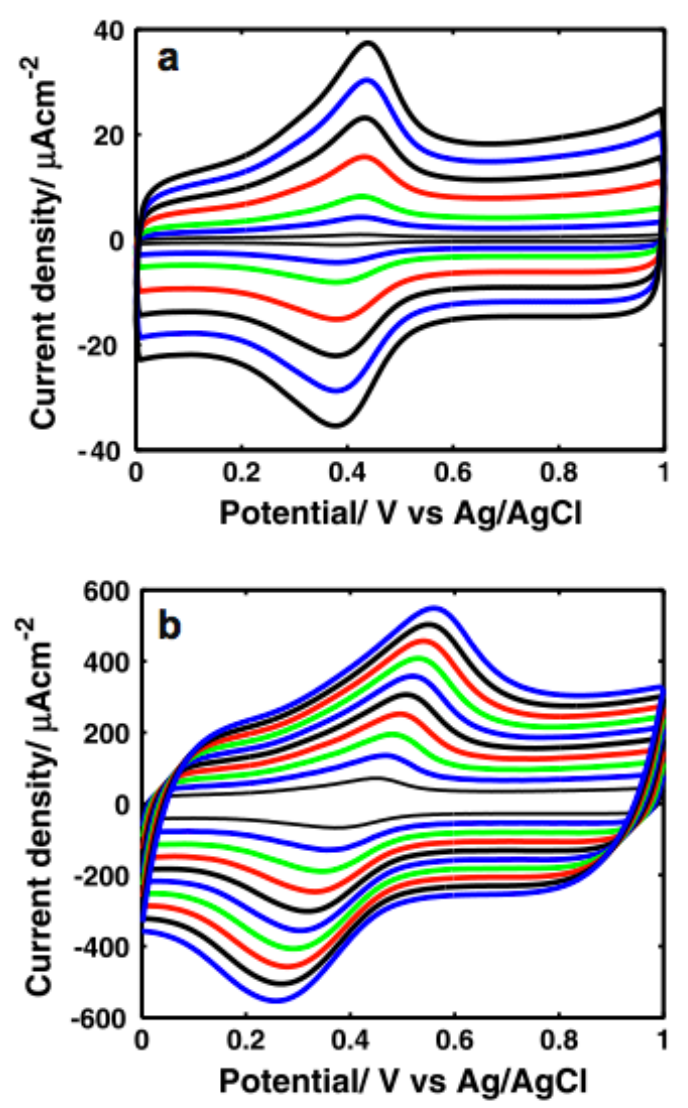

Fig. 4 - Cyclic voltammograms of graphene electrodes before annealing (DC conductivity of $859 \mathrm{~S} \mathrm{~m}^{-1}$ ) at increasing voltage scan rates of (a) $10,50,100,200,300,400$, and $500 \mathrm{mV} \mathrm{s}^{-1}$, and (b) 1000, 2000, 3000, 4000, 5000, 6000, 7000, $8000,9000,10,000 \mathrm{mV} \mathrm{s}^{-1}$.

electrical conductivity; (2) minimized resistance because of nanometer-scale thickness electrodes, as shown later by electrical conductivity and EIS measurements; (3) and the use of an electrolyte with high ionic conductivity.

Geometric capacitance $C_{s}$ of the electrode films is used in this work to avoid inaccuracies related to the mass determination of the ultra-thin graphene electrodes, and is given by: $C_{s}\left(F^{-2}\right)=\frac{1}{2} \int I d t / A \Delta V$ where $I$ is current $(A), t$ is time (s), $A$ is the electrode geometric area $\left(1 \mathrm{~cm}^{2}\right)$, and $\Delta V$ is the voltage window $(1 \mathrm{~V})$. A plot of geometric capacitance versus scan rate of the graphene electrodes is shown in Fig. 5a. The highest capacitance at the lowest scan rate of $10 \mathrm{mV} \mathrm{s}^{-1}$ was $543 \mu \mathrm{F} \mathrm{cm}^{-2}\left(15.6 \mathrm{~F} \mathrm{~cm}^{-3}\right.$ for an electrode thickness of $350 \mathrm{~nm}$ ), decreasing by $43 \%$ to $309 \mu \mathrm{F} \mathrm{cm}^{-2}$ at $10,000 \mathrm{mV} \mathrm{s}^{-1}$, as shown in Fig. $5 \mathrm{~b}$. The capacitance retention was superior to other graphene-oxide-derived "graphene" electrodes where capacitance faded by $35 \%$ at a comparatively slow scan rate of $800 \mathrm{mV} \mathrm{s}^{-1}$ [56]. The performance here was comparable with high performance pseudocapacitive $\mathrm{RuO}_{2}$ that had $53 \%$ capacitance retention at $10,000 \mathrm{mV} \mathrm{s}^{-1}$ [57]. For comparison, Fig. $5 b$ shows a similar plot for carboxylated-SWCNT spraydeposited $550 \mathrm{~nm}$ thick electrodes that had an almost complete capacitance fading ( $85 \%)$ by $4,000 \mathrm{mV} \mathrm{s}^{-1}$, suggesting that the high power of the graphene electrodes cannot be attributed solely to their thin film character.
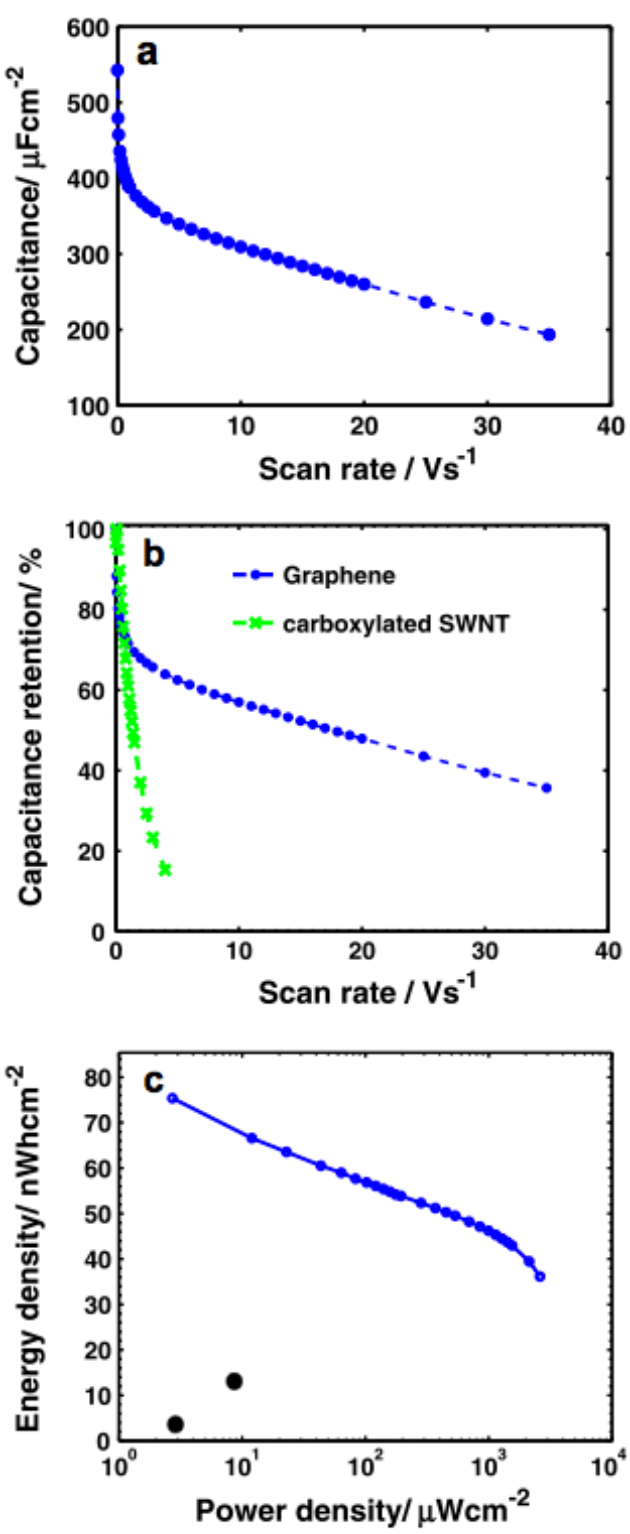

Fig. 5 - Plots of (a) geometric capacitance as a function of scan rate for a graphene electrode, and (b) capacitance retention as a function of scan rate for a graphene and a carboxylated SWCNT electrodes, and (c) ragone plot normalized by geometric electrode area for a graphene electrode. The solid dots represent previously reported data for thin graphene electrodes [19].

The energy density and power density of the graphene electrodes are shown in the ragone plot in Fig. 5c, where energy and power densities were calculated from cyclic voltammetry data as follows: $E\left(\mathrm{Whcm}^{-2}\right)=\frac{1}{2} \mathrm{C}_{s} \Delta \mathrm{V}^{2}$ and $\mathrm{P}\left(\mathrm{Wcm}{ }^{-2}\right)=\frac{E}{t}$ where $\mathrm{C}_{\mathrm{s}}$ is the geometric capacitance $\left(\mathrm{F} \mathrm{cm}^{-2}\right), \mathrm{t}$ is the time for the cathodic sweep in a voltammogram (h), and $\Delta V$ is defined as before. The data points correspond to voltage scan rates from 10 to $20,000 \mathrm{mV} \mathrm{s}^{-1}$. The energy density of the graphene electrode followed a gradually decreasing trend with a maximum of $75.4 \mathrm{nW} \mathrm{h} \mathrm{cm}{ }^{-2}$ at power density of $2.7 \mu \mathrm{W} \mathrm{cm} \mathrm{cm}^{-2}$, and a maximum power density of $2.6 \mathrm{~mW} \mathrm{~cm}^{-2}$ at $36.1 \mathrm{nW} \mathrm{h} \mathrm{cm}{ }^{-2}$. 
Corresponding peak capacitance $\left(C_{M}\right)$, energy density $\left(E_{M}\right)$ and power density $\left(\mathrm{P}_{\mathrm{M}}\right)$ per unit mass were estimated as $\mathrm{C}_{M} \approx 18 \mathrm{~F} \mathrm{~g}^{-1}$ (from cyclic voltammetry at a scan rate of $\left.10 \mathrm{mV} \mathrm{s}^{-1}\right), \mathrm{E}_{\mathrm{M}} \approx 2.5 \mathrm{Wh} \mathrm{kg}^{-1}$, and $\mathrm{P}_{\mathrm{M}} \approx 86.8 \mathrm{~kW} \mathrm{~kg}^{-1}$. We are cautious in cross-comparing these per unit mass values with those in the literature because of inherent problems in determining accurately the mass of all thin film electrodes, as recognized in previous work where suitable metrics are used to characterize ultra-thin electrochemical capacitors electrodes $[58,19,3]$. In any case, irrespective of mass, the peak geometric capacitance reported here of $543 \mu \mathrm{F} \mathrm{cm}^{-2}\left(15.6 \mathrm{~F} \mathrm{~cm}^{-3}\right)$ is the highest so far reported for ultra-thin graphene electrodes: Yoo et al. and Wang et al. reported geometric capacitances of $394 \mu \mathrm{F} \mathrm{cm}^{-2}$ and $279 \mu \mathrm{F} \mathrm{cm} \mathrm{cm}^{-2}$ respectively [19,59]. Markedly, EIS studies showed that the capacitance of our spray deposited graphene exfoliated flakes lying predominantly in the plane of the electrode was $221.9 \mu \mathrm{F} \mathrm{cm}^{-2}$ at $0.01 \mathrm{~Hz}$ which is 1.1 times greater than $195.0 \mu \mathrm{F} \mathrm{cm}{ }^{-2}$ (capacitance of a single electrode of $2 \mathrm{~cm}^{2}$ in a symmetric full cell of $\approx 390 \mu \mathrm{F}$ capacitance, i.e. $97.5 \mu \mathrm{F} \mathrm{cm}^{-2}$ when normalized per $4 \mathrm{~cm}^{2}$ area of 2 electrodes) at $0.01 \mathrm{~Hz}$ reported for vertically aligned PECVD grown graphene [3]. In both cases, no capacitance saturation was observed at $0.01 \mathrm{~Hz}$. As shown in Fig. 5c, both the energy and power density of our graphene electrodes were higher than those reported in the literature of $14 \mathrm{nW} \mathrm{h} \mathrm{cm}{ }^{-2}$, and $9 \mu \mathrm{W} \mathrm{cm}^{-2}$ for ultra-thin graphene electrochemical capacitors [19].

A geometric capacitance of $543 \mu \mathrm{F} \mathrm{cm}^{-2}$ is however in the low range when compared with mesoporous carbon materials such as networks of carbon nanotubes and activated carbon with higher energy density inherent to their porous nature (high surface area), although these carbon forms have poorer power density performance (higher ionic resistance) than graphene [3]. The particularly high power density of our electrodes derives from the non-porous and highly conductive nature of the non-defective exfoliated graphene - it is too pristine to provide a high energy density, but ideal to provide high power density. Further supporting this view, it is known that the reactive sites of several forms of $\mathrm{sp}^{2}$ hybridized carbon, including highly ordered pyrolytic carbon and carbon nanotubes, reside on the edge planes populated with surface defects rather than the basal planes free of defects [60], therefore suggesting that the relatively low capacitance observed in our graphene electrodes is correlated to the absence of basal plane defects having a charge storage contribution only from edge defects. On the other hand, adding a degree of non-subnanometer scale porosity to graphene would substantially increase capacitance while keeping a high power density as indicated by the behaviour of porous carbon-onions containing less than $5 \%$ subnanometer micropores [21,22].

Sodium cholate $(\mathrm{NaC})$ is the corresponding salt of cholic acid used in the graphene exfoliation and consists of a steroid nucleus (hydrophobic face) with three hydroxyl groups (hydrophilic face) and an aliphatic chain terminated with a carboxylic group [54]. It is thus considered an amphiphilic molecule where the hydrophobic face of $\mathrm{NaC}$ interacts with graphene during exfoliation whereas the hydrophilic face provides compatibility with the aqueous environment having an overall encapsulation-like interaction with graphene that produces a stabilizing effect $[54,55]$. Therefore, the NaC-graphene interaction likely leads to $\mathrm{NaC}$ entrapped between graphene layers after spraying giving rise to the redox peaks in the cyclic voltammograms which coincided with typical redox activity of oxygen functionalities on carbon surfaces in acidic media $(0.4 \mathrm{~V}$ vs. $\mathrm{Ag} / \mathrm{AgCl})[61,62]$. In order to confirm the contribution of residual $\mathrm{NaC}$ to capacitive behavior, a spray-deposited graphene electrode was annealed at $500^{\circ} \mathrm{C}$ for $4 \mathrm{~h}$ in a hydrogen/argon (10\%/90\%) atmosphere [32] and Fig. 6 shows a cyclic voltammogram of the annealed electrode. The redox peaks previously attributed to residual $\mathrm{NaC}$ almost completely disappeared suggesting that redox activity was associated to residual $\mathrm{NaC}$ functional groups.

Investigation of the electrical properties of the electrodes showed a direct current (DC) conductivity of $859 \mathrm{~S} \mathrm{~m}^{-1}$ and $4905 \mathrm{~S} \mathrm{~m}^{-1}$ before and after annealing respectively. These DC conductivity values are much higher than those previously reported for graphene oxide derived electrodes of $100 \mathrm{~S} \mathrm{~m}^{-1}$, and $500 \mathrm{~S} \mathrm{~m}^{-1}[28,23]$, and supports further the maintenance of a large fraction of the $\mathrm{sp}^{2}$ bonding configuration of graphene. We suggest that the high quality of graphene underpins the high power performance of the electrodes. Furthermore, conductivity measurements suggest that higher power performances than shown in Fig. 4 can be expected upon annealing-driven removal of $\mathrm{NaC}$, albeit with an unavoidable loss of the pseudocapacitance contribution to charge storage.

Although a contribution to electrochemical behavior from $\mathrm{NaC}$ should be expected - and residual $\mathrm{NaC}$ is required to inhibit graphene restacking - it was unexpected that the pseudocapacitive activity could be maintained without significant resistive behavior up to $10,000 \mathrm{mV} \mathrm{s}^{-1}$, as shown in Fig. 4. Except for nanostructured $\mathrm{RuO}_{2}$ [57] such high power density is not widely reported, for either metal oxides or other pseudocapacitive groups on carbon-based materials. One implication of this result may be that when pristine graphene is used as substrate for pseudocapacitive materials or other compounds with electrochemically active groups, the underlying graphene can help delay the onset of resistive behaviour at very high scan rates. This approach could help increase the other-

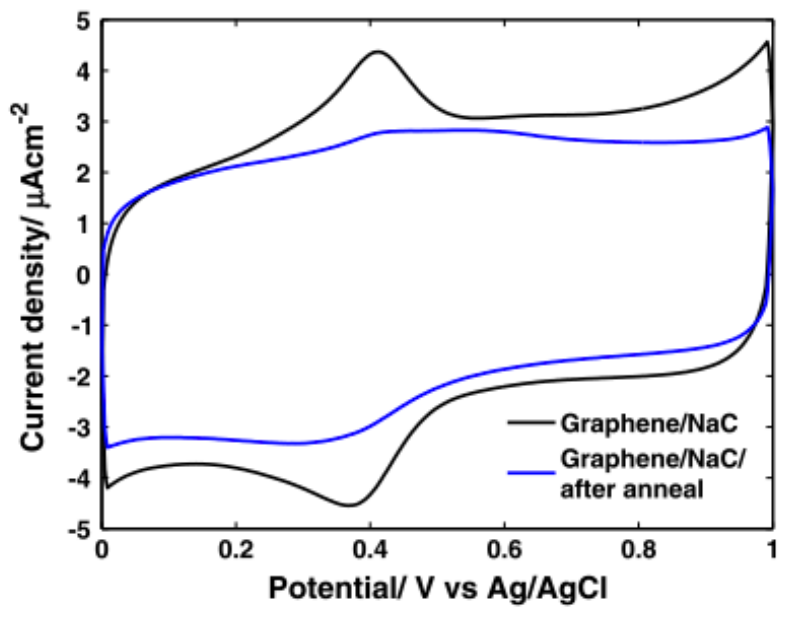

Fig. 6 - Cyclic voltammograms of graphene/NaC electrodes before and after annealing at $500^{\circ} \mathrm{C}$ in a $\mathrm{H}_{2} / \mathrm{Ar}(10 \% / 90 \%)$ atmosphere for $4 \mathrm{~h}$. The voltage scan rate is $50 \mathrm{mV} \mathrm{s}^{-1}$. 
wise comparatively poor energy density of graphene electrodes, and facilitate the development of systems that offer a better balance of energy and power densities.

Galvanosatic charge/discharge studies for the graphene electrodes were performed at current densities of 25$400 \mu \mathrm{A} \mathrm{cm}^{-2}$, and charge/discharge curves for the first cycles at $25 \mu \mathrm{A} \mathrm{cm}^{-2}$ are shown in Fig. 7a. There were two regimes of behavior, from 1 to $0.4 \mathrm{~V}$ and from 0.4 to $0 \mathrm{~V}$. The inflection point at $0.4 \mathrm{~V}$ describes the redox activity due to $\mathrm{NaC}$ previously observed by cyclic voltammetry. Discharge curves of the 10th cycle at current densities of $25,50,100,200$, and $400 \mu \mathrm{A} \mathrm{cm}^{-2}$ are shown in Fig. 7b. Underscoring their high power density performance, the discharging times of the graphene electrodes $(31.1,14,6.6,3.1$, and $1.4 \mathrm{~s}$ for current densities of $25,50,100,200$, and $400 \mu \mathrm{A} \mathrm{cm}^{-2}$, respectively) were at least one order of magnitude shorter than those reported in the literature to date $[25,28,19,20]$.

Impedance spectroscopy studies of graphene electrodes were performed from $0.01 \mathrm{~Hz}$ to $200 \mathrm{kHz}$ at an AC voltage of $5 \mathrm{mV} \mathrm{rms}$. In order to investigate both the double layer and pseudocapacitance energy storage mechanisms, a DC voltage of $0.396 \mathrm{~V}$ was applied. We applied the methodology proposed by Sugimoto et al. for analysis of the impedance data dividing it into different frequency regions (time scales) where different mass and charge transport processes dominate [63]. Fig. 8 shows the different frequency regions in the Nyquist plot for a graphene electrode. The knee-frequency and characteristic frequency were $12.7 \mathrm{kHz}$ and $57.8 \mathrm{~Hz}$, respectively. The high
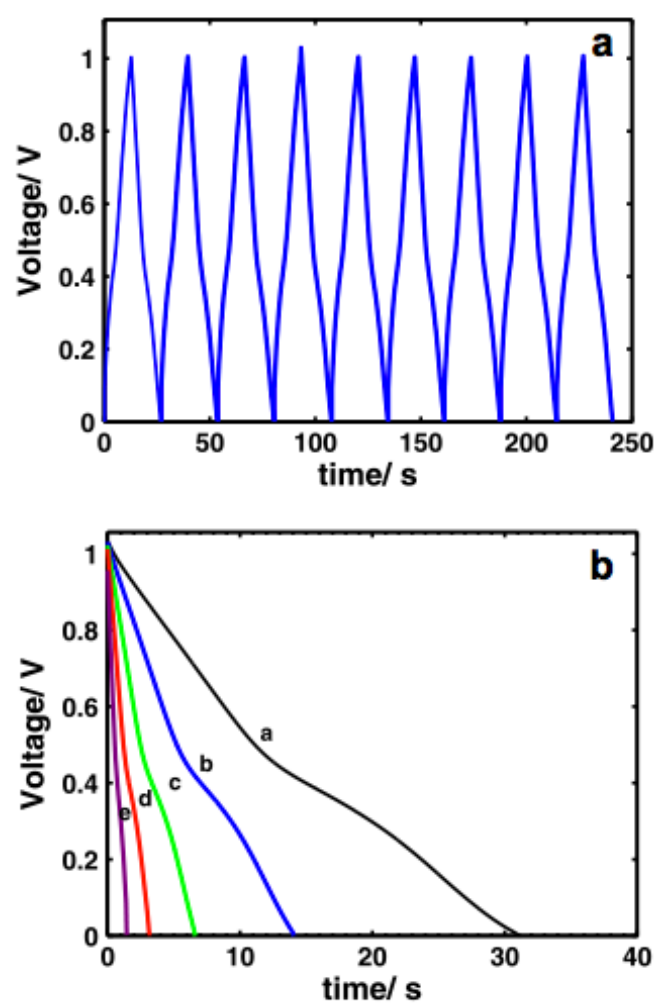

Fig. 7 - Galvanostatic charge-discharge curves of (a) a graphene electrode during first cycles at $50 \mu \mathrm{A} \mathrm{cm} \mathrm{cm}^{-2}$; (b) a graphene electrode for the 10 th cycle at increasing current densities of 25 (a), 50 (b), 100 (c), 200 (d), and 400 (e) $\mu \mathrm{A} \mathrm{cm}^{-2}$. frequency region $(200 \mathrm{kHz}<f<12.7 \mathrm{kHz})$ in Fig. $8 \mathrm{~b}$ showed a depressed semicircle, better described as a low gradient plot running almost parallel to the real axis $Z^{\prime}$, revealing the low impedance at the electrode-electrolyte interface. Best fitting of the data at high frequency was performed using the equivalent circuit $R_{s}\left(\mathrm{CPE}_{f}\left(\mathrm{R}_{f}\right)\right)\left(\mathrm{CPE}_{d l}\left(\mathrm{R}_{\mathrm{ct}} \mathrm{Z}_{\mathrm{w}}\right)\right)$, where $R_{s}$ represents the resistive contribution from the electrolyte, $C P E_{f}$ and $R_{f}$ are a constant phase element and a resistance, respectively, representing the electrical equivalent of the film as a whole, $C P E_{d l}$ is the double layer capacitance, $R_{c t}$ is the charge transfer resistance of pseudocapacitive processes, and $Z_{W}$ is the impedance of a finite length Warburg element representing diffusion processes of the electrolyte ions into the film [64] (see Supporting Information). A low charge transfer resistance was estimated from the fit, $R_{\mathrm{ct}}=1.0 \Omega$, providing evidence of the fast kinetics of the pseudocapacitive activity. As compared with other
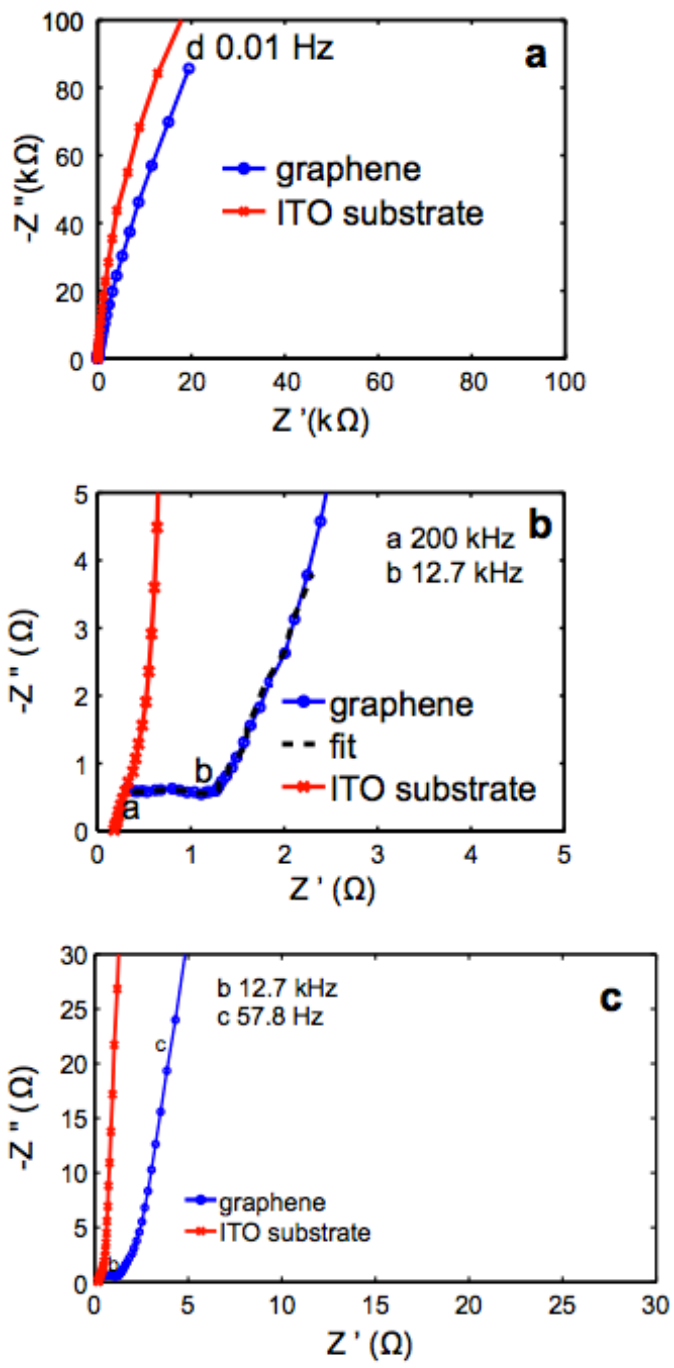

Fig. 8 - (a) Nyquist plot of a graphene electrode and a bare ITO coated glass substrate performed at $5 \mathrm{mV}$ rms AC voltage in the frequency range of $0.01 \mathrm{~Hz}$ to $200 \mathrm{kHz}$, close ups of (b) high, and (c) medium frequency ranges. Annotations indicate (a) maximum frequency, (b) kneefrequency, (c) characteristic frequency, and (d) lowest frequency. 

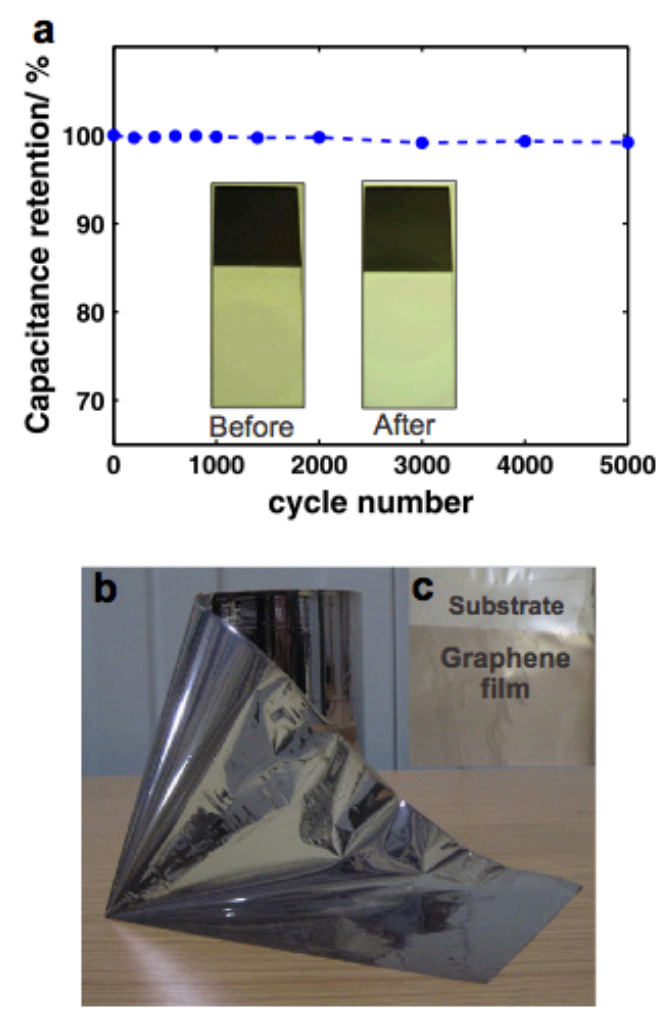

Fig. 9 - (a) Capacitance retention of a graphene electrode upon cyclic voltammetry at $10,000 \mathrm{mV} \mathrm{s}^{-1}$ for 5000 cycles; the inset shows optical images of the graphene electrode before and after cycling, (b) A $0.15 \mathrm{~m} \times 1 \mathrm{~m}$ graphene electrode deposited onto an aluminum coated PET web.

carbon materials, $R_{c t}$ for the graphene electrode was one order of magnitude lower than that reported for multi-walled carbon nanotubes and carbon black functionalized with oxygencontaining chemical groups $(23-29 \Omega)$ [64]. The medium frequency region $(12.7 \mathrm{kHz}<f<57.8 \mathrm{~Hz}$ ) shown in Fig. $8 \mathrm{c}$ followed a nearly vertical trend indicating capacitive behavior. Notice that the EIS behavior of the graphene electrode is due to the electroactive material and not to the ITO coated glass substrate as evidenced by EIS studies carried out under identical conditions on a bare ITO coated glass substrate and shown in Fig. 8. The Nyquist plot in Fig. $8 \mathrm{c}$ shows a nearly pure capacitive behavior at high frequencies for the ITO coated glass susbstrate.

The capacitor response, defined as the inverse of the characteristic frequency, was determined as $17.4 \mathrm{~ms}$ and was comparable with that of anhydrous pseudocapacitive $\mathrm{RuO}_{2}(10$ $20 \mathrm{~ms}$ ) [63]. Further optimization of the electrode performance included the improvement of the electrical contact between the current collector and the electroactive material by excluding the PEI precoating, annealing for $\mathrm{NaC}$ removal, and decreasing of the electrode thickness to $40 \mathrm{~nm}$. These changes resulted into an even faster capacitor response of $2.3 \mathrm{~ms}$. Recently, Miller et al. suggested the application of a graphene double layer capacitor for filtering voltage ripple for which a pure capacitive behavior (phase angle near $-90^{\circ}$ ) is needed at high frequency [3]. A phase angle of $-82^{\circ}$ at $120 \mathrm{~Hz}$ was reported for vertically plasma enhanced CVD grown graphene directly on current collectors whereas we obtained a slightly lower phase angle of $-72^{\circ}$ at $120 \mathrm{~Hz}$ for exfoliated and sprayed graphene electrodes (see Supporting Information).

The cyclability of the graphene electrodes was examined by cyclic voltammetry and galvanostatic charge/discharge experiments. There was approximately $100 \%$ capacitance retention after 5000 cycles at a comparatively high scan rate of $10,000 \mathrm{mV} \mathrm{s}^{-1}$, as shown in Fig. 9a. Similarly, there was an approximately $100 \%$ capacitance retention following charge-discharge experiments at 50 and $100 \mu \mathrm{A} \mathrm{cm}^{-2}$ for 1000 cycles (see Supporting information).

\subsection{Scaleability}

Finally, the scaleability of the spray deposition manufacturing method was demonstrated for a $0.15 \mathrm{~m} \times 1 \mathrm{~m}$ graphene electrode spray-deposited onto an aluminum coated PET flexible substrate as shown in Fig. $9 \mathrm{~b}$ and $\mathrm{c}$.

\section{Conclusions}

Typically $350 \mathrm{~nm}$ thick graphene electrochemical capacitor electrodes with outstanding power performance and excellent cyclability demonstrated by cyclic voltammetry and galvanostatic charge-discharge experiments have been manufactured by the combination of aqueous exfoliation followed by spray deposition. Unlike electrochemical capacitor electrodes manufactured with graphene-oxide derived graphene, double layer capacitance and pseudocapacitance were maintained up to unusually high scan rates of $10,000 \mathrm{mV} \mathrm{s}^{-1}$, giving a peak power density of $2.6 \mathrm{~mW} \mathrm{~cm}^{-2}$ and significantly out-performing similar electrodes using functionalized single-walled nanotubes. The use of comparatively pristine graphene underpinned the high scan rate pseudocapacitance of residual exfoliant species, which made a useful contribution to overall capacitance at all scan rates. Electrochemical impedance spectroscopy analysis showed a charge transfer resistance of $1 \Omega$ and a fast capacitor response of $17.4 \mathrm{~ms}$ which was further improved to $2.3 \mathrm{~ms}$ for the thinnest $40 \mathrm{~nm}$ electrodes after annealing. Near $100 \%$ capacitance retention at $10,000 \mathrm{mV} \mathrm{s}^{-1}$ was demonstrated. The aqueous exfoliation and spray deposition manufacturing route was shown to be easily scaleable, and offers the potential for low cost processing of graphene electrodes with ultrahigh power density for niche applications.

\section{Acknowledgements}

The authors thank financial support of the Mexican National Council of Science and Technology (CONACYT), UK Engineering and Physical Science Research Council (Supergen Energy Storage, EP/HO19596), and the Mathematics, Physical and Life Sciences division, Oxford University. The authors gratefully acknowledge Dr. Luca Minati (Fondazione Bruno Kessler, Trento, Italy) for his kind help with XPS.

\section{Appendix A. Supplementary data}

Supplementary data associated with this article can be found, in the online version, at http://dx.doi.org/10.1016/j.carbon. 2012.09.035. 
[20] Liu C, Yu Z, Neff D, Zhamu A, Jang BZ. Graphene-based supercapacitor with an ultrahigh energy density. Nano Lett 2010;10(12):4863-8.

[1] Kötz R, Carlen M. Principles and applications of electrochemical capacitors. Electrochim Acta 2000;45(1516):2483-98.

[2] Miller JR, Simon P. Electrochemical capacitors for energy management. Science 2008;321(5889):651-2.

[3] Miller JR, Outlaw RA, Holloway BC. Graphene double-layer capacitor with ac line-filtering performance. Science 2010;329(5999):1637-9.

[4] Conway BE. Electrochemical supercapacitors: scientific fundamental and technological applications. New York, USA: Kluwer Academic/ Plenum Publishers; 1999.

[5] Simon P, Gogotsi Y. Materials for electrochemical capacitors. Nat Mater 2008;7(11):845-54.

[6] Zhao X, Mendoza-Sánchez B, Dobson PJ, Grant PS. The role of nanomaterials in redox-based supercapacitors for next generation energy storage devices. Nanoscale 2011;3(3):839-55.

[7] Novoselov KS, Geim AK, Morozov SV, Jiang D, Katsnelson MI, Grigorieva IV, et al. Two-dimensional gas of massless dirac fermions in graphene. Nature 2005;438(7065): 197-200.

[8] Novoselov KS, Geim AK, Morozov SV, Jiang D, Zhang Y, Dubonos SV, et al. Electric field effect in atomically thin carbon films. Science 2004;306(5696):666-9.

[9] Geim AK, Novoselov KS. The rise of graphene. Nat Mater 2007;6(3):183-91.

[10] Zhang Y, Tan YW, Stormer HL, Kim P. Experimental observation of the quantum hall effect and berry's phase in graphene. Nature 2005;438(7065):201-4.

[11] Pisana S, Lazzeri M, Casiraghi C, Novoselov KS, Geim AK, Ferrari AC, et al. Breakdown of the adiabatic bornoppenheimer approximation in graphene. Nat Mater 2007;6(3):198-201.

[12] Chmiola J, Largeot C, Taberna PL, Simon P, Gogotsi Y. Monolithic carbide-derived carbon films for microsupercapacitors. Science 2010;328(5977):480-3. http:// dx.doi.org/10.1126/science.1184126.

[13] Futaba DN, Hata K, Yamada T, Hiraoka T, Hayamizu Y, Kakudate Y, et al. Shape-engineerable and highly densely packed single-walled carbon nanotubes and their application as super-capacitor electrodes. Nat Mater 2006;5(12):987-94. http://dx.doi.org/10.1038/nmat1782.

[14] Pushparaj VL, Shaijumon MM, Kumar A, Murugesan S, Ci L, Vajtai R, et al. Flexible energy storage devices based on nanocomposite paper. Proc Natl Acad Sci USA 2007;104(34):13574-7. http://dx.doi.org/10.1073/ pnas. 0706508104 .

[15] Kords K, Mustonen T, Tth G, Jantunen H, Lajunen M, Soldano $\mathrm{C}$, et al. Inkjet printing of electrically conductive patterns of carbon nanotubes. Small 2006;2(8-9):1021-5.

[16] Pech D, Brunet M, Taberna PL, Simon P, Fabre N, Mesnilgrente $\mathrm{F}$, et al. Elaboration of a microstructured inkjet-printed carbon electrochemical capacitor. J Power Sources 2010;195(4):1266-9.

[17] Pech D, Brunet M, Durou H, Huang P, Mochalin V, Gogotsi Y, et al. Ultrahigh-power micrometre-sized supercapacitors based on onion-like carbon. Nat Nano 2010;5(9):651-4. http:// dx.doi.org/10.1038/nnano.2010.162.

[18] Sun W, Chen X. Fabrication and tests of a novel three dimensional micro supercapacitor. Microelectron Eng 2009;86(4-6):1307-10.

[19] Yoo JJ, Balakrishnan K, Huang J, Meunier V, Sumpter BG, Srivastava A, et al. Ultrathin planar graphene supercapacitors. Nano Lett 2011;11(4):1423-7.

[21] Portet C, Yushin G, Gogotsi Y. Electrochemical performance of carbon onions, nanodiamonds, carbon black and multiwalled nanotubes in electrical double layer capacitors. Carbon 2007;45(13):2511-8.

[22] Portet C, Chmiola J, Gogotsi Y, Park S, Lian K. Electrochemical characterizations of carbon nanomaterials by the cavity microelectrode technique. Electrochim Acta 2008;53(26):7675-80.

[23] Zhu Y, Murali S, Stoller MD, Ganesh KJ, Cai W, Ferreira PJ, et al. Carbon-based supercapacitors produced by activation of graphene. Science 2011;332(6037):1537-41.

[24] Byon HR, Lee SW, Chen S, Hammond PT, Shao-Horn Y. Thin films of carbon nanotubes and chemically reduced graphenes for electrochemical micro-capacitors. Carbon 2011;49(2):457-67.

[25] Vivekchand S, Rout C, Subrahmanyam KS, Govindaraj A, Rao CNR. Graphene-based electrochemical supercapacitors. J Chem Sci 2008;120(1):9-13.

[26] Subrahmanyam KS, Vivekchand SRC, Govindaraj A, Rao CNR A study of graphenes prepared by different methods: characterization, properties and solubilization. J Mater Chem 2008;18(13):1517-23.

[27] Stankovich S, Dikin DA, Piner RD, Kohlhaas KA, Kleinhammes A, Jia Y, et al. Synthesis of graphene-based nanosheets via chemical reduction of exfoliated graphite oxide. Carbon 2007;45(7):1558-65.

[28] Wang Y, Shi Z, Huang Y, Ma Y, Wang C, Chen M, et al. Supercapacitor devices based on graphene materials. J Phys Chem C 2009;113(30):13103-7.

[29] Stoller MD, Park SJ, Zhu YW, An JH, Ruoff RS. Graphene-based ultracapacitors. Nano Lett 2008;8(10):3498-502.

[30] Zhu Y, Murali S, Stoller MD, Velamakanni A, Piner RD, Ruoff RS. Microwave assisted exfoliation and reduction of graphite oxide for ultracapacitors. Carbon 2010;48(7):2118-22.

[31] Li X, Zhang G, Bai X, Sun X, Wang X, Wang E, et al. Highly conducting graphene sheets and langmuir-blodgett films. Nat Nanotechnol 2008;3(9):538-42.

[32] De S, King PJ, Lotya M, O'Neill A, Doherty EM, Hernandez Y, et al. Flexible, transparent, conducting films of randomly stacked graphene from surfactant-stabilized, oxide-free graphene dispersions. Small 2010;6(3):458-64.

[33] Yu D, Dai L. Self-assembled graphene/carbon nanotube hybrid films for supercapacitors. J Phys Chem Lett 2009;1(2):467-70.

[34] Lotya M, King PJ, Khan U, De S, Coleman JN. Highconcentration, surfactant-stabilized graphene dispersions. ACS Nano 2010;4(6):3155-62.

[35] Lotya M, Hernandez Y, King PJ, Smith RJ, Nicolosi V, Karlsson LS, et al. Liquid phase production of graphene by exfoliation of graphite in surfactant/water solutions. J Am Chem Soc 2009;131(10):3611-20.

[36] Mendoza-Sánchez B, Minati L, Grant PS. A scalable spray deposition route for the fabrication of nanocomposite supercapacitor electrodes. In: Fourth european symposium on super capacitors and applications. Bordeaux, France: Proceedings; 2010.

[37] Zhao X, Chu BTT, Ballesteros B, Wang WL, Johnston C, Sykes JM, et al. Spray deposition of steam treated and functionalized single-walled and multi-walled carbon nanotube films for supercapacitors. Nanotechnology 2009;20(6):065605.

[38] Ballesteros B, Tobias G, Shao L, Pellicer E, Nogues J, Mendoza E, et al. Steam purification for the removal of graphitic shells coating catalytic particles and the shortening of singlewalled carbon nanotubes. Small 2008;4(9):1501-6. 
[39] Tobias G, Lidong S, Salzmann C, Huh Y, Green M. Purification and opening of carbon nanotubes using steam. J Phys Chem 2006;110:22318-22.

[40] Pauw VdL. A method of measuring specific resistivity and hall effect of discs of arbitrary shape. Philips Res Rep 1958;13(1):1-9.

[41] Hernandez Y, Nicolosi V, Lotya M, Blighe FM, Sun Z, De S, et al. High-yield production of graphene by liquid-phase exfoliation of graphite. Nat Nanotechnol 2008;3(9):563-8.

[42] Meyer JC, Geim AK, Katsnelson MI, Novoselov KS, Obergfell D, Roth S, et al. On the roughness of single- and bi-layer graphene membranes. Solid State Commun 2007;143(1-2):101-9.

[43] Meyer JC, Geim AK, Katsnelson MI, Novoselov KS, Booth TJ, Roth S. The structure of suspended graphene sheets. Nature 2007;446(71-31):60-3.

[44] Horiuchi S, Gotou T, Fujiwara M, Sotoaka R, Hirata M, Kimoto $\mathrm{K}$, et al. Carbon nanofilm with a new structure and property. Jpn J Appl Phys 2003;42(Part 2, No. 9A/B):L1073-L1076.

[45] Murphy H, Papakonstantinou P, Okpalugo TIT. Raman study of multiwalled carbon nanotubes functionalized with oxygen groups. J Vac Sci Technol B 2006;24(2):715-20.

[46] Yang D, Velamakanni A, Bozoklu G, Park S, Stoller M, Piner $\mathrm{RD}$, et al. Chemical analysis of graphene oxide films after heat and chemical treatments by X-ray photoelectron and micro-Raman spectroscopy. Carbon 2009;47(1):145-52.

[47] Haubner K, Murawski J, Olk P, Eng LM, Ziegler C, Adolphi B, et al. The route to functional graphene oxide. ChemPhysChem 2010;11(10):2131-9.

[48] Ferrari AC, Meyer JC, Scardaci V, Casiraghi C, Lazzeri M, Mauri F, et al. Raman spectrum of graphene and graphene layers. Phys Rev Lett 2006;97(18):187401.

[49] Kudin KN, Ozbas B, Schniepp HC, Prud'homme RK, Aksay IA, Car R. Raman spectra of graphite oxide and functionalized graphene sheets. Nano Lett 2007;8(1):36-41.

[50] Ago H, Kugler T, Cacialli F, Salaneck WR, Shaffer MSP, Windle $\mathrm{AH}$, et al. Work functions and surface functional groups of multiwall carbon nanotubes. J Phys Chem B 1999;103(38):8116-21.

[51] Weng L, Poleunis C, Bertrand P, Carlier V, Sclavons M, Franquinet $P$, et al. Sizing removal and functionalization of the carbon fiber surface studied by combined TOF SIMS and XPS. J Adhes Sci Technol 1995;9(7):859-71.

[52] Diez-Pascual AM, Martinez G, Gonzalez-Dominguez JM, Anson A, Martinez MT, Gomez MA. Grafting of a hydroxylated poly(ether ether ketone) to the surface of single-walled carbon nanotubes. J Mater Chem 2010;20(38):8285-96.

[53] López GP, Castner DG, Ratner BD. XPS o 1s binding energies for polymers containing hydroxyl, ether, ketone and ester groups. Surf Interface Anal 1991;17(5):267-72.

[54] Mukhopadhyay S, Maitra U. Chemistry and biology of bile acids. Curr Sci India 2004;87(12):1666-83.

[55] Green AA, Hersam MC. Solution phase production of graphene with controlled thickness via density differentiation. Nano Lett 2009;9(12):4031-6.

[56] Lv W, Tang DM, He YB, You CH, Shi ZQ Chen XC, et al. Lowtemperature exfoliated graphenes: vacuum-promoted exfoliation and electrochemical energy storage. ACS Nano 2009;3(11):3730-6.

[57] Lin KM, Chang K, Hu CC, Li YY. Mesoporous ruo2 for the next generation supercapacitors with an ultrahigh power density. Electrochim Acta 2009;54(19):4574-81.

[58] Lee SW, Kim BS, Chen S, Shao-Horn Y, Hammond PT. Layerby-layer assembly of all carbon nanotube ultrathin films for electrochemical applications. J Am Chem Soc 2008;131(2):671-9.

[59] Wang DW, Li F, Wu ZS, Ren W, Cheng HM. Electrochemical interfacial capacitance in multilayer graphene sheets: Dependence on number of stacking layers. Electrochem Commun 2009;11(9):1729-32.

[60] Banks CE, Davies T], Wildgoose GG, Compton RG. Chem. Comm. 2005;7:829-41.

[61] Frackowiak E, Béguin F. Carbon materials for the electrochemical storage of energy in capacitors. Carbon 2001;39(6):937-50.

[62] Andreas HA, Conway BE. Examination of the double-layer capacitance of an high specific-area c-cloth electrode as titrated from acidic to alkaline PHS. Electrochim Acta 2006;51(28):6510-20.

[63] Sugimoto W, Iwata H, Yokoshima K, Murakami Y, Takasu Y. Proton and electron conductivity in hydrous ruthenium oxides evaluated by electrochemical impedance spectroscopy: the origin of large capacitance. J Phys Chem B 2005;109(15):7330-8.

[64] Obradovic MD, Vukovic GD, Stevanovic SI, Panic VV, Uskokovic PS, Kowal A, et al. A comparative study of the electrochemical properties of carbon nanotubes and carbon black. J Electroanal Chem 2009;634(1):22-30. 